\title{
Raíces ignacianas del papa Francisco
}

\section{Víctor Codina, S. J.}

Quizás pueda llamar la atención hablar de las raíces ignacianas del papa Francisco, pues da la impresión de que tanto por su nombre como por su actitud ecológica está más cerca de Francisco de Asís que de Ignacio de Loyola. De todas maneras, no podemos olvidar que aquel tuvo un papel importante en la conversión de Ignacio y que la espiritualidad que Ignacio vivió en el seno de su familia de Loyola era fuertemente franciscana.

Sin negar esa proximidad y simpatía hacia Francisco de Asís, cabe preguntarnos si en los casi cuarenta años vividos en las comunidades de la Compañía de Jesús, desde 1953 a 1992 (fecha en que fue nombrado obispo auxiliar de Buenos Aires), sus dos meses de Ejercicios, su trabajo como maestro de novicios, rector de formación y provincial en Argentina, no han dejado huella en él.

Veamos algunos rasgos de la espiritualidad ignaciana para preguntarnos luego si los podemos hallar en el papa Francisco, hoy.

\section{Partir de la realidad}

En la Iglesia ha habido estilos de espiritualidades muy diferentes. Los primitivos monjes se iban al desierto huyendo del mundo para encontrar a Dios en la soledad y la oración. En la edad media, los mendicantes - franciscanos y dominicos - comunican al pueblo lo que han contemplado en silencio. Ignacio tiene otra postura, más moderna y más actual, encuentra a Dios en el mundo, no solo en la naturaleza, sino también en la historia, en los acontecimientos.

Una experiencia mística que tuvo siendo laico, en la ciudad de Manresa, junto al río Cardoner, le abrió los ojos: todo le pareció nuevo. Vio cómo toda la historia estaba como bañada por la luz de Dios y formaba parte del proyecto del Dios creador, redentor y santificador. Nada era profano, todo estaba dentro del amor de Dios, del Dios de la vida. 
Precisamente, este partir de la realidad hace que Ignacio sea muy consciente, por su propia experiencia de conversión en Loyola y Montserrat, de que nuestra realidad, de hecho, está marcada por el pecado, contrario al proyecto de Dios. Por esto, los Ejercicios comienzan con la "primera semana", que trata del pecado, del mal del mundo y de la necesidad de cambiar esta historia de pecado. Se comienza con la negatividad para superarla. También en la contemplación de la encarnación se comienza viendo la realidad, la redondez de la tierra, con personas tan diversas en trajes, gestos, blancos y negros, unos en paz, otros en guerra, unos llorando, otros riendo, unos sanos, otros enfermos, unos naciendo, otros muriendo... (EE 106). Todo esto es un llamado a la conversión, al cambio, a la reforma.

Y ello desde la perspectiva del perdón y de la misericordia. La primera semana acaba con un coloquio de misericordia y gratitud ante el Señor crucificado y con la pregunta de qué hemos de hacer por Cristo.

Ignacio, ciertamente, es consciente de que la reforma no solo debe ser personal, sino eclesial y social. En su tiempo, fue un gran reformador eclesial, pero quiere comenzar la reforma por el cambio personal, por la reforma de vida personal.

Francisco ha heredado este realismo ignaciano, enriquecido por la metodología de América Latina de ver-juzgar-actuar. En Evangelii gaudium (La alegría del evangelio), Francisco afirma que la realidad es superior a la idea, la idea desconectada de la realidad produce idealismos y nominalismos (EG 232-233). Por esto, parte de la realidad social y eclesial.

Comienza su pontificado con la herencia de Benedicto XVI, de una Iglesia en crisis: la barca de la Iglesia parece que se hunde, muchos la dejan en silencio, hay escándalos sexuales y financieros, se vive una atmósfera de invierno eclesial.

En La alegría del evangelio, Francisco critica la economía de exclusión, la idolatría del dinero, la inequidad que genera violencia. También critica algunas posturas eclesiales: la acedia egoísta, el pesimismo estéril, la mundanidad espiritual, las divisiones y guerras internas en la Iglesia (EG 52-109).

A los miembros de la curia vaticana les advierte de quince peligros o tentaciones: el sentirse inmortales, inmunes a toda crítica, indispensables hasta caer en la patología del poder; el excesivo activismo en detrimento de otras dimensiones humanas necesarias; la fosilización mental, que conduce a falta de sensibilidad humana ante los problemas de los demás, que impide llorar con los que lloran y reír con los que ríen; la excesiva planificación y funcionalidad burocrática; la mala coordinación con otros grupos; el alzhéimer espiritual, que lleva a olvidar las raíces de la propia identidad y a ser esclavos de los ídolos fabricados por nosotros mismos; la rivalidad y la vanagloria; la esquizofrenia existencial, que produce una doble vida y lleva a la hipocresía; los chismes y las murmuraciones de los demás; el divinizar a los jefes, esperando su benevolencia; la indiferencia ante los problemas de los demás; la arrogancia y rigidez adusta; el 
ansia de acumular bienes materiales; el mantener un círculo cerrado de poder; y el exhibicionismo y la búsqueda de poder.

Este realismo lo lleva, en Laudato si', sobre el cuidado de la casa común, a contemplar lo negativo que ocurre en nuestra casa común: el cambio climático, la cultura del descarte, la contaminación del agua y los océanos, la pérdida de la biodiversidad, el deterioro de la calidad de vida y la degradación social, la injusticia que recae en los más pobres, sin que los dirigentes mundiales tomen resoluciones valientes ( $L S$ 22-59). Todo ello se debe a una absolutización de la idea del progreso tecnocrático, que hace que no se miren los daños sociales y ecológicos. Por esto es necesario un cambio radical del estilo de vida, abandonar el antropocentrismo radical y convertirse a un estilo de vida más sencillo, más sobrio y solidario, respetuoso de nuestra casa común.

Por todo ello, Francisco desea una reforma de la Iglesia y de la sociedad, y hace un llamado a la conversión, a una impostergable renovación y reforma eclesial. Una conversión fundamentada en la misericordia de Dios, siempre más dispuesto a perdonarnos que nosotros a pedir perdón, y proclama el jubileo de la misericordia para llamar a todos a la conversión.

Como Ignacio, Francisco está convencido de que es necesaria una conversión personal, social y eclesial para revertir el sentido de la historia, comenzando por cada uno de nosotros, pues sin hombres y mujeres nuevos, no tendremos un mundo diferente y mejor.

La Congregación General 34 de la Compañía de Jesús declara que ser jesuita significa reconocer que uno es pecador y, sin embargo, llamado a ser compañero de Jesús, como Ignacio. Esta insistencia de Francisco en que recemos por él, ¿no reflejará esta convicción ignaciana de que todos somos pecadores y necesitamos experimentar la misericordia de Dios y una continua conversión?

\section{Experiencia espiritual}

Si la experiencia es un conocimiento interno de las cosas, de forma no solo teórica, sino también práctica, una sabiduría, la experiencia espiritual es tener, de algún modo, una experiencia de los misterios de la fe cristiana, de Cristo, del evangelio, de Dios. Es algo común a todas las grandes religiones y al cristianismo. Sin experiencia espiritual, no hay teología, no hay apostolado, no hay comunidad, no hay cristianismo maduro. Se ha dicho que en nuestro mundo secularizado y agnóstico de hoy, el cristiano será un místico o será un ateo. Ignacio es un maestro de la experiencia espiritual, un mistagogo, que nos inicia en esta experiencia espiritual.

Ignacio fue un hombre de profunda experiencia espiritual, desde su conversión hasta el final de su vida, desde Manresa a Roma, desde el Cardoner a la Storta. Toda su vida está marcada por gracias espirituales y místicas. 
Es un místico. Dios lo guiaba como un maestro de escuela guía a un niño. Los Ejercicios que Ignacio vivió y escribió son una escuela de experiencia espiritual para todos los cristianos, una iniciación a la experiencia espiritual, una mistagogía, no es un libro de lectura, ni de doctrina, sino de experiencia espiritual.

Por eso, Ignacio, en los Ejercicios, insiste en que no el mucho saber harta y satisface el alma, sino el sentir y gustar internamente de las cosas (Anotación 2). Le dice al que da los Ejercicios que no interfiera con el ejercitante, sino que deje que el mismo Criador y Señor se comunique inmediatamente con su criatura (Anotación 15).

Francisco es heredero de esta tradición espiritual y mistagógica y no se cansa de repetir las palabras de Benedicto XVI en Dios es amor (n. 1): "No se comienza a ser cristiano por una decisión ética o una gran idea, sino por el encuentro con un acontecimiento, con una Persona, que da un nuevo horizonte a la vida, y con ello una orientación decisiva".

Está convencido de que el gran riesgo del mundo actual es el consumismo, que produce una tristeza individualista, que brota del corazón cómodo y avaro, de la búsqueda de placeres superficiales y de la conciencia aislada ( $E G$ 2). Por eso, invita a cada cristiano "a renovar ahora mismo su encuentro personal con Jesucristo o, al menos, tomar la decisión de dejarse encontrar por Él" (EG 3).

Su pastoral no es predominantemente doctrinal ni magisterial, como la de pontificados anteriores, sino que es una pastoral iniciática, que invita a la experiencia espiritual. Este encuentro con el Señor

... se convierte en feliz amistad, somos rescatados de nuestra conciencia aislada y de la autorreferencialidad. Llegamos a ser plenamente humanos cuando somos más que humanos, cuando le permitimos a Dios que nos lleve más allá de nosotros mismos para alcanzar nuestro ser verdadero ( $E G 8)$.

Esta experiencia del evangelio, personificado en Jesús, es la fuente de la alegría y la fuente de donde nace la evangelización. Se comunica a otros la experiencia alegre que hemos tenido. Toda la exhortación La alegría del evangelio nace de esta convicción de la importancia de la experiencia espiritual. Esta es la alegría que hace que no seamos cristianos con cara de cuaresma sin pascua, ni cara de funeral, sino cristianos con la alegría del evangelio.

La alegría constante y comunicativa de Francisco nace de esta convicción y de esta experiencia espiritual, alimentada por espacios de silencio, de oración y contemplación del Señor.

¿No refleja esta insistencia de Francisco en la experiencia espiritual la tradición ignaciana de los Ejercicios, que él ha experimentado durante tantos años? 


\section{Profundo amor personal a Jesús}

Ignacio, ya desde su conversión, al leer la Vida de Cristo, comenzó a sentir un amor profundo y personal a Jesús, su Salvador, su Criador y Señor, el que murió para salvarnos del pecado y de la muerte, el que nos llama al reino. Ignacio decide seguir a Jesús, agradecido de que Cristo le haya perdonado sus pecados, y repregunta ¿qué hago, qué he hecho y qué debo hacer por Cristo?

Por eso, Ignacio desea conocer la tierra de Jesús, Palestina, y quedarse a vivir y trabajar allí, como lo hicieron los apóstoles. Va a Tierra Santa, se entusiasma contemplando los lugares donde vivió Jesús y se siente muy afligido cuando le prohíben quedarse. Y no descarta la posibilidad de regresar a Jerusalén. Solo cuando sus compañeros no pueden ir, por falta de embarcación, se ponen a las órdenes del papa para que como pastor universal les diga dónde tienen que trabajar.

Ignacio siente un gran apasionamiento por Jesús y quiere que su orden no se llame la orden de Ignacio, sino la Compañía de Jesús. Esta centralidad de Jesús en la espiritualidad ignaciana tiene como tres pasos sucesivos:

1. Conocimiento interno de Jesús, es decir, experiencia interna de quién es Jesús y de lo que hizo, tal como se nos revela en los evangelios. Es un conocimiento interno, fruto de la lectura de las Escrituras y de la oración.

2. Amor a Jesús, es decir, entusiasmo, cariño, intimidad, como de amigo a Amigo, de hermano a Hermano, de salvado a Salvador, de perdonado a Perdonador, de criatura a Criador, un amor que llegue a la afectividad, a la sensibilidad, al corazón. El conocimiento interno desemboca en el amor. Ignacio, aparentemente tan austero y seco, es un gran enamorado del Señor, como los grandes enamorados de la historia: Pablo, Agustín, Francisco, Domingo, Teresa de Jesús, Charles de Foucauld, etc. Ignacio derrama abundantes lágrimas en sus oraciones y misas, lleno de amor a Jesús.

3. Seguimiento de Jesús, es decir, no simplemente imitación de lo que hizo, sino seguir su proyecto, su misión, el trabajo por el reino de Dios. Este seguimiento implica seguir sus opciones, su estilo de vida, su camino hacia la pascua. La espiritualidad ignaciana es una espiritualidad cristocéntrica del seguimiento de Jesús.

Francisco, frente a las posturas tradicionales, obsesionadas por la ortodoxia doctrinal y el moralismo de la casuística, sobre todo, en temas sexuales, cree que la Iglesia ha de difundir, ante todo, el perfume del evangelio de Jesús, la alegría de la salvación en Cristo, anunciar la buena noticia de Jesús de Nazaret, iniciar a la experiencia espiritual del encuentro con el Señor. Francisco pasa de un magisterio doctrinal y moral, al kerigma, es decir, al anuncio del evangelio, al anuncio de Jesús. 
Hay que concentrarse en lo esencial del evangelio, en lo más bello y atractivo, hablar más de la gracia que de la ley, hablar más de Cristo que de la Iglesia, más de la Palabra de Dios que del papa. Mantener la jerarquía de verdades, la novedad del evangelio, la alegría de la pascua.

Por eso, su magisterio resulta, para muchos, singularmente para los jóvenes, como algo nuevo con frescura de evangelio. Frente a los que lo aclaman diciendo: ¡Francisco, Francisco!, él les dice que digan: ¡Jesús, Jesús!

\section{Seguimiento de Jesús humilde y pobre}

La espiritualidad ignaciana es una espiritualidad del seguimiento personal de Jesús, pero del Jesús histórico, pobre y humilde de Nazaret, un seguimiento que lleva hasta la cruz. Ignacio, después de su conversión, se volvió un humilde peregrino, que vivía de limosna y trabajaba en los hospitales. Más adelante, cuando se unió con otros y fundó una orden religiosa, en Roma, siguió con su apostolado entre las prostitutas y las jóvenes en peligro, y les dice a los jesuitas de Padua que "la amistad con los pobres nos hace amigos del Rey eterno". Y a Laynez y Salmerón, teólogos de Trento, les dice que han de vivir en hospitales y dar catecismo a los niños.

Por eso, el seguimiento supone optar por los pobres y marginados de nuestro mundo y llevar una vida pobre y humilde, como fue la de Jesús de Nazaret, que no tenía dónde reclinar su cabeza.

Este seguimiento del Jesús pobre es muy importante en América Latina, donde la gran mayoría del pueblo es pobre y marginado. La espiritualidad ignaciana, sobre todo, a la luz de Medellín y Puebla, se convierte en América Latina en una espiritualidad del seguimiento de Jesús, en la lucha por la justicia, en la construcción de un reino de vida, en medio de un mundo de muerte, en liberación de todas las esclavitudes que sufre el pueblo, en integración de todos los excluidos y marginados de la sociedad.

Todo ello se reforzó en la Congregación General 32 de la Compañía de Jesús (1974-1975), que redefinió el carisma de los jesuitas como el trabajo por la fe y la lucha por la justicia, es decir, une fe y justicia para los excluidos. Al hacer esa opción, la Congregación era consciente de que habría de pagar un costo social grande, como de hecho sucedió. Desde 1974 hasta nuestros días, más de 70 jesuitas han sido asesinados por predicar el evangelio unido a la justicia. Entre ellos, Luis Espinal, Ignacio Ellacuría y los mártires de la UCA de El Salvador.

Francisco ha optado por el método de Jesús, que hablaba en parábolas y hacía signos del reino. También él hace signos nazarenos del reino: besar a un niño discapacitado y abrazar a un hombre con la cara totalmente deformada, lavar los pies a una joven musulmana, comer en Asís con niños con síndrome de Down, en su primer viaje fuera de Roma, visitar la isla de Lampedusa y lanzar una corona 
de flores amarillas y blancas, en memoria de los inmigrantes fallecidos, usar sus zapatos viejos de antes, en vez de los zapatos rojos de su antecesor, no vivir en los palacios apostólicos del Vaticano, sino en la residencia de Santa Marta, viajar por Roma en un sencillo y pequeño coche utilitario para no escandalizar a la gente de los barrios periféricos populares, invitar para su cumpleaños a cuatro mendigos...

Lo que Francisco dice y hace no es otra cosa que traducir el evangelio al mundo de hoy: está más preocupado del hambre del mundo que de los problemas internos de la Iglesia, sueña que la Iglesia sea una Iglesia pobre y para los pobres...

Estos gestos evangélicos están acompañados de reflexiones evangélicas y de denuncias proféticas: el poder ha ser estar al servicio de los pobres, de los más débiles y más pequeños; la crisis financiera actual no es solo económica, sino también antropológica: es el olvido de las personas humanas para idolatrar al dinero, el nuevo becerro de oro, que reduce al ser humano a mero consumidor, a un producto que se puede usar y luego tirar. En Lampedusa, Francisco hace un fuerte alegato contra la insensibilidad humana, que tiene el corazón anestesiado frente a la tragedia de tantos hermanos africanos y asiáticos, que acuden a las costas europeas, en busca de mejores días de vida, pero mueren en el mar o son devueltos a sus países de origen. Y exclama: ¡es una vergüenza!

No es casual que Bergoglio, siendo provincial de los jesuitas de Argentina, asistiera a la Congregación General 34, que redefinió el carisma de la Compañía como defensa de la fe y promoción de la justicia. No es casual que, siendo obispo de Buenos Aires, conociera y visitara continuamente las villas en miseria de la capital y que apoyase a los curas villeros, que las atienden pastoralmente.

Su exhortación apostólica La alegría del evangelio tiene palabras muy duras contra el sistema económico y político actual. Es una economía que mata, los excluidos no solo son explotados, sino que también son desechados, masas sobrantes. Es una economía de la exclusión y la inequidad, de la idolatría del dinero. El afán de poder y de riqueza lo domina todo, tiende a fagocitarlo todo. Hay que decir no a un dinero que gobierna en lugar de servir, que manipula y degrada a las personas. El sistema social y económico actual es injusto, genera desigualdad y violencia, promueve la exacerbación del consumo, crece el cáncer de la corrupción (EG 52-60). La propuesta evangélica no es solo de una relación personal con Dios, sino que también la realización del reino y su justicia ( $E G$ 176-181). Cada comunidad cristiana debe analizar la situación de su país y sacar las consecuencias pastorales y sociales (EG 182-185).

Asimismo, Francisco destaca el lugar privilegiado de los pobres en el pueblo de Dios. Los pobres tienen mucho que enseñarnos y debemos dejarnos evangelizar por ellos, recoger la misteriosa sabiduría que Dios quiere comunicarnos a 
través de ellos ( $E G$ 198). Por eso, hay que valorar muy positivamente la piedad popular, verdadero lugar teológico al cual debemos prestar atención (EG 122-126).

Estos pobres tienen rostros concretos, que hoy día revisten nuevas formas de pobreza y de fragilidad: los sin techo, los tóxico-dependientes, los refugiados, los pueblos indígenas, los ancianos abandonados, los migrantes, las víctimas de la trata de personas, las mujeres que sufren exclusión, maltrato y violencia, los niños por nacer. La misma creación es víctima de la explotación y la pobreza (EG 209-215). Todo esto lo desarrolla en Laudato si', donde une el clamor de la creación con el clamor de los pobres. Los pobres son las primeras víctimas de la explotación de la naturaleza.

De todo ello, Francisco saca consecuencias para la Iglesia. Esta ha de ser como un hospital de campaña, que sana heridas; ha de salir a la calle, ir a las fronteras existenciales, aun con peligro de accidentes; reconocer que todos somos hijos e hijas del mismo Padre y hermanos y hermanas, una Iglesia con entrañas maternales de misericordia, que refleje la ternura de Dios y cuide de la creación. La Iglesia no puede ser restauracionista, ni añorar el pasado. Los pastores han de oler a oveja y no convertirse en clérigos de despacho o coleccionistas de antigüedades, ni caer en el carrerismo. Los obispos no pueden estar siempre en los aeropuertos...

¿Es casual que en el viaje a Bolivia, Francisco haya hecho una parada junto al lugar donde fue asesinado su compañero jesuita Luis Espinal, por predicar un evangelio unido a la justicia, que haya hablado en contra de la lógica del descarte, que se haya reunido con los movimientos populares que demandan tierra, techo y trabajo, que haya visitado a los reclusos de Palmasola, en Santa Cruz, y les haya abrazado con cariño?

¿No ha actuado en todo ello como discípulo de aquel peregrino pobre y mendigo que seguía al Jesús pobre y humilde, que se llamó Íñigo de Loyola?

\section{El reino como proyecto de Jesús}

Ignacio, al leer la vida de Cristo y de los santos en Loyola, sintió un gran atractivo por la figura de Jesús, que marcó el cristocentrismo de su espiritualidad, tal como ya hemos visto.

No obstante, la devoción de Ignacio a la humanidad Jesús, que tiene sin duda raíces medievales (Bernardo, Francisco, Kempis...), se abre a una dimensión nueva, más moderna: Jesús tiene un proyecto, el reino de Dios, el proyecto del Padre de construir una humanidad reconciliada, filial y fraternal, donde reine la justicia y la paz, la vida en abundancia... No se trata solo de contemplar a Jesús, ni de imitarlo simplemente, sino de seguirlo en su proyecto. Un seguimiento que no es meramente ético o moral, sino espiritual. Una identificación con Cristo, una vida en Cristo, movida por el mismo Espíritu que guio toda la vida de Jesús. 
Y este proyecto de Jesús es el reino. Por lo tanto, no se limita a edificar la Iglesia, sino que quiere construir un mundo nuevo y diferente. Un reino integral, que incluye lo social, lo político, lo cultural, lo económico, lo ecológico y lo religioso. Para el seguidor de Jesús, trabajar en lo social, en la justicia, en la política, en la ciudadanía..., no es desviarse de su misión, sino realizar el proyecto del Padre, el reino de Dios, en colaboración con otros. El reino es una invitación, un llamado, una vocación, que se puede traducir en campos diversos, no solo en el campo eclesial. El optar por el trabajo social, político, educativo, de salud no es una simple profesión, es una vocación del Señor, una misión.

No basta sentirnos consolados contemplando al Señor, sino que hemos de preguntarnos qué quiere de nosotros. Para Ignacio hay dos palabras clave en su espiritualidad: ayudar y servir.

Francisco orienta toda la actividad de la Iglesia a la misión. La Iglesia no ha de esperar a que lleguen de afuera a su puerta, sino que ha de salir a la calle, ir a las periferias, a las fronteras geográficas y existenciales, aun con el riesgo de accidentarse. Es una Iglesia en salida, misionera.

No es una Iglesia encerrada en sí misma, autorreferencial, es decir, preocupada tan solo de sí misma, de sus escándalos o de sus problemas clericales..., sino una Iglesia que busca lo perdido, que sale al encuentro del necesitado, que atraviesa los caminos polvorientos del mundo, que quiere escuchar el clamor del pueblo, sus dificultades y anhelos, como hacía Jesús de Nazaret, al recorrer los caminos de Galilea o Judea.

Es una Iglesia en estado de misión, que callejea la fe y que quiere acudir a las encrucijadas de la historia y dialogar con la ciencia, con las culturas, con las religiones, sin miedo, porque sabe que el Espíritu del Señor llena el universo y es causa de toda novedad.

Esto hace que la Iglesia no añore el pasado, sino que se abra al futuro y a los signos de los tiempos, a los nuevos areópagos.

Es una Iglesia hospital de campaña. La Iglesia tiene que socorrer hoy las emergencias personales y sociales, salvar, curar, suturar, vendar las heridas del sufrimiento humano y espiritual, salvar las vidas amenazadas de niños, mujeres, indígenas, ancianos, discapacitados, sanar cicatrices de personas que sufren en su cuerpo o en su espíritu. Es lo que hacía Jesús por los caminos de Palestina. Ahora, la Iglesia es la que se preocupa de nuestra casa común, tal como aparece en Laudato si'.

\section{Sentido eclesial}

Ignacio, hasta su conversión, era un cristiano popular de fe profunda, pero de vida moral muy libre, con un sentido eclesial poco profundo y una práctica 
eclesial seguramente un tanto ocasional. A partir de su conversión y de su atracción por Jesús y su reino, poco a poco, va comprendiendo la estrecha relación entre Jesús y la Iglesia, entre Jesús y la comunidad. Al no poderse quedar en Jerusalén, tal como deseaban tanto él como sus compañeros, se abre a la dimensión eclesial. Así, de Jerusalén pasa a Roma, todos ellos se ponen en manos del papa y acaban haciendo un voto de obediencia a este acerca de las misiones que les encomiende.

En los Ejercicios, Ignacio propone las reglas para sentir con, o mejor, en la Iglesia, y afirma que entre Cristo y su Esposa la Iglesia es el mismo Espíritu el que nos gobierna ( $E E$ 365). Esta postura eclesial es la que distingue a Ignacio de otros reformadores, que rompieron con la Iglesia. Y aunque tuvo grandes problemas e incluso sufrió cárceles por causa de la inquisición y tensiones con Pablo IV, murió pidiendo la bendición del papa, aun sabiendo que la Iglesia estaba gobernada por un pontífice que no apreciaba a la Compañía y que podía disolverla, pero al que la Compañía había hecho voto de obediencia.

En la espiritualidad ignaciana hay una tensión entre el reino y la Iglesia, entre una misión universal abierta al estilo paulino y una obediencia eclesial al estilo petrino. Ni una Iglesia sin reino, ni un reino al margen o contra la Iglesia. Un mismo Espíritu es quien une a la Iglesia y al reino.

Y para Ignacio hay una figura que une a Jesús con la Iglesia, María, a quien siempre tuvo una especial devoción.

Este sentido eclesial ignaciano lo ha heredado Bergoglio, lo ha acrecentado como obispo de Buenos Aires y, finalmente, como obispo de Roma, con la diferencia de que antes hacía voto de obediencia al papa y ahora es él el que rige los destinos de la misión eclesial. Pero lo hace convencido de que es un mismo Espíritu el que nos rige a todos en la Iglesia, cualquiera que sea nuestro carisma o función en ella.

La preocupación eclesial de Francisco es, ante todo, un deseo de reformar la Iglesia, en las personas y sus estructuras, en la base y la cúspide. Desde aquí se comprenden sus críticas a la mundanidad espiritual y a todos los vicios y las tentaciones que acosan a la Iglesia, como el poder, el carrerismo, la autorreferencialidad, la acedia, etc. Desde aquí se comprende la importancia que da a la misión evangelizadora de la Iglesia.

Pero su eclesialidad está fundamentada en la acción del Espíritu del Resucitado en la Iglesia, fuente de esperanza y consuelo, aun en los momentos de crisis. El último capítulo de La alegría del evangelio está dedicado a los evangelizadores con Espíritu.

Francisco también tiene una profunda devoción mariana con raíces ignacianas, y enriquecida por la tradición mariana latinoamericana. 


\section{Buscar la voluntad de Dios}

Cuando Ignacio, convaleciente en Loyola, comienza a pensar en su futuro, piensa en qué querrá Dios de él. Toda su vida es una peregrinación hacia Dios, buscando siempre lo que desea de él. Ignacio es un maestro en la búsqueda de la voluntad de Dios.

Por eso, los Ejercicios ignacianos se orientan a la elección, a buscar qué es lo que Dios quiere de nosotros en la vida. La realidad, el pecado, la conversión y la invitación del reino piden una respuesta personal, que solo nosotros mismos podemos dar. En esto, Ignacio es moderno, valora la libertad, la autonomía y la conciencia personal. ¿Qué he de hacer por Cristo, qué respuesta doy a su invitación al seguimiento en el proyecto del reino? Mi libertad está situada en la historia, en el hoy y aquí. Dios cuenta con nosotros, no podemos evadirnos, no podemos pecar de omisión, hay que ayudar a Dios.

Al principio, piensa en ir a Jerusalén para ayudar a las almas, como Jesús, pero cuando le prohíben quedarse, se pregunta qué tiene que hacer. Entonces, decide estudiar en Barcelona, Alcalá, Salamanca, París... Luego, comienza a reunir a algunos compañeros con la idea de ir a Jerusalén. Cuando no pueden ir, se preguntan qué hacer y van al papa para que les señale la voluntad de Dios. Enseguida se preguntan si el grupo de compañeros debe permanecer unido y formar una orden religiosa con superior encargado del grupo o si deben separarse y disolverse. Decidieron permanecer juntos y formar un cuerpo apostólico con obediencia a uno de ellos. Aun siendo ya general de la Compañía de Jesús, Ignacio busca lo que Dios quiere de su grupo. Reza y celebra misas para que el Señor lo ilumine, al escribir las Constituciones de la orden. Toda su vida es una búsqueda de la voluntad de Dios.

Los mismos Ejercicios, que hace y escribe, ofrecen un método para ayudar a encontrar la voluntad de Dios en la vida. Una vez finalizados aquellos, el ejercitante concluye con la oración que ha pasado a ser conocida como oración de san Ignacio: "Tomad, Señor, y recibid toda mi libertad, mi memoria, mi entendimiento, toda mi voluntad, todo mi haber y mi poseer, Vos me los disteis, a Vos, Señor, lo torno, todo es vuestro, dadme vuestro amor y vuestra gracia, que ésta me basta" (EE 234).

Y en sus cartas, siempre acaba pidiendo a Dios que su santísima voluntad conozcamos y fielmente la cumplamos.

Pero Ignacio, buen psicólogo, sabe que para hallar esta voluntad hay que tener una sensibilidad especial. No dejarse llevar por primeras impresiones, buscar el proyecto de Dios, buscar siempre la mayor gloria de Dios, lo que más conduce al fin para el cual hemos sido creados. Por eso, Ignacio nos da criterios de discernimiento, reglas de discernimiento del espíritu, que él mismo ha ido aprendiendo en su propia experiencia desde Loyola. 
Poco a poco, fue descubriendo que Dios nos llama a la alegría y a la paz verdadera, a la vida y al gozo auténtico y a la consolación. En cambio, todo lo que conduce a la tristeza y la angustia, a la desolación y a la muerte, no es de Dios, sino del maligno. Para Ignacio, sentir gozo en el seguimiento de Jesús es señal del buen espíritu y de que nos guía el Señor. La falsa alegría, la falsa consolación, no es de Dios, sino engaño del maligno.

Por eso, Ignacio puede ser un maestro y un modelo para que podamos descubrir la voluntad de Dios sobre nosotros mismos, sobre nuestra comunidad, sobre nuestro tiempo, y para conocer los signos de los tiempos.

Francisco también ha heredado este sentido de libertad y responsabilidad personal, este deseo de hallar la voluntad de Dios y de discernir los signos de los tiempos hoy. También para él la alegría del evangelio es señal del buen espíritu.

Y sin duda, ha tenido que hacer y hace un discernimiento sobre lo que Dios quiere de la Iglesia de hoy. Los pasos dados indican que ha ido discerniendo el pasar de una Iglesia moralista a una Iglesia que anuncia el kerigma, el evangelio; de una Iglesia doctrinal a una Iglesia que invita a la experiencia espiritual, a la mistagogía; de una Iglesia cerrada a una Iglesia de puertas abiertas; de una Iglesia autorreferencial a una Iglesia que sale a la calle y huele a oveja, hospital de campaña para curar heridas; de una Iglesia de control y aduana sacramental a una Iglesia de la misericordia y la ternura de Dios; de una Iglesia de príncipes y monseñores y de curas capataces a una Iglesia de pastores servidores del pueblo; de una Iglesia que prescinde de los laicos a una Iglesia que quiere vivir el sentido comunitario y sinodal de todo el pueblo de Dios, movido por el Espíritu; de una Iglesia con nostalgia del pasado a una Iglesia del Vaticano II, abierta a los signos de los tiempos.

Y la alegría, el gozo y la consolación que han causado estas decisiones y discernimientos de Francisco son señal clara de que han sido buenas elecciones. Hemos pasado del invierno a la primavera eclesial.

\section{Contemplativos en la acción}

Para Ignacio, no hay dos historias, la profana y la sagrada, ni se puede decir que a Dios solo lo podemos encontrar en la oración, la liturgia y la soledad del silencio. Si hemos discernido cuál es la voluntad de Dios para nosotros, entonces podemos hallar a Dios en todas las cosas que se orienten al reino. Podemos ser contemplativos en la familia, en el trabajo, en la política, en la lucha contra la injusticia, en la liberación, en la ecología... Es lo que Nadal, uno de los primeros jesuitas, llama ser contemplativos en la acción.

En la Contemplación para alcanzar amor (EE 230-237), Ignacio nos muestra a un Dios presente en la creación, que habita en sus criaturas, en los elementos 
a los que da el ser, en los vegetales, los animales, en las personas, hechas a su imagen y semejanza. Dios trabaja y actúa en la creación, en la vida.

Y este Dios cuenta con nosotros, porque el amor se pone más en obras que en palabras. Ignacio dirá que en todo hay que amar y servir.

Esto configura una espiritualidad profundamente histórica, dinámica, secular, laical y ecológica.

Francisco, en Laudato si', sigue el ejemplo de Francisco de Asís y de su cántico a las criaturas, seguramente mucho más bello y poético que las expresiones de Ignacio, en su contemplación para alcanzar amor.

Pero esta sensibilidad de Francisco hacia la casa común se nutre no solo de la captación de la realidad actual, sino que también tiene raíces del Ignacio que encuentra a Dios en todas las cosas y que espera respuesta nuestra, porque el amor se pone más en las obras que en las palabras. Todo el capítulo 2 de Laudato si', el evangelio de la creación, tiene mucha sintonía con la visión ignaciana de la creación y de la presencia de Dios en ella. No es casual que Francisco cite, además de Basilio, Dante y santo Tomás, al jesuita científico y místico de la creación Teilhard de Chardin ( $L S$ 83), cuya "Misa sobre el mundo" concuerda con el Himno a la creación de Francisco de Asís.

Pero también es ignaciano procurar que estas bellas consideraciones bíblicas y teológicas sobre la creación no queden en el aire, sino que se concreten en un cambio de vida. De ahí la necesidad de una conversión a la ecología integral y de una educación y espiritualidad ecológicas (capítulos 4 y 6).

El realismo ignaciano, la exigencia de conversión y de reforma, la iniciación en la experiencia espiritual, el cristocentrismo de un seguimiento del Jesús pobre y humilde de Nazaret, la llamada del reino, el sentir eclesial, la búsqueda de la voluntad de Dios y el deseo de hallar a Dios en todas las cosas, características de la espiritualidad ignaciana que Bergoglio ha vivido durante décadas, se encuentran presentes en la pastoral y en la espiritualidad del papa Francisco.

No es una simple yuxtaposición externa, sino una asimilación vital, que asume otros componentes relacionados con la espiritualidad franciscana, con la pastoral de la Iglesia de América Latina, con teólogos como Romano Guardini o Juan Carlos Scannone.

La síntesis no es tanto una esfera cuanto un poliedro, como Francisco gusta afirmar (EG 236), donde se mantiene la diversidad en la unidad, unidad que es vivir la alegría del evangelio del Señor. Y todo ello nos produce lo que Ignacio llama consolación. 